\title{
Correlation of Yolk Sac Diameter on TVS with Fetal Outcome
}

\author{
Dr. Manchanda Prabhjot (DNB) ${ }^{1}$, Dr. Birla Nandini (MS) ${ }^{2}$, Dr. Dharamdasani Megha (DNB) ${ }^{3}$, \\ Dr. Shetty Nidhi (DGO) ${ }^{4}$
}

\begin{abstract}
Objective: To investigate the role of yolk sac diameter in between 9-10 weeks of gestation by TVS in prediction of pregnancy in an unselected population. Design: Prostective observational clinical study of 100 cases. Setting: Hindustan Aeronautics Ltd Hospital, Bangalore, Karnataka. Material \& method: The study of 100 singleton pregnancies has been conducted at HAL hospital, Bangalore. Women attending routine ANC clinics were offered an early TVS of 3.4-5 MHz transducer between 9-10 weeks of gestation. Results: 100 patients were screened for yolk sac diameter by subjecting them to TVS at 9-10 weeks at HAL hospital, Bangalore \& followed up till delivery. All the 73 cases with yolk sac diameter 2-6mm had successful pregnancy outcome. Cases out of 22 cases with yolk sac diameter $>6 \mathrm{~mm}, 19$ had missed abortion leaving $100 \%$ sensitivity of abnormal yolk sac diameter with poor pregnancy outcome and a p value of significant $<0.001$. Conclusions: Yolk sac diameter at 9-10 weeks of gestation between 2-6 mm is significant to conclude successful pregnancy outcome. Yolk sac diameter $>6 \mathrm{~mm}$ is a good predictor of poor pregnancy outcome with sensitivity $100 \%$, specificity $96.3 \%$, PPV $86.36 \%$, NPV $100 \%$, accuracy $97 \%$.
\end{abstract}

Keywords: YSD, abortion, TVS, pregnancy outcome, Prostective observational clinical study

\section{Introduction}

Pregnancy is the biggest physiological upheaval of a woman's life. Accurate differentiation between normal pregnancy and pregnancy loss in early gestation is a clinical challenge. It is estimated that $30-40 \%$ of implanted pregnancies result in spontaneous abortion during first trimester. In first trimester yolk sac is primary source of exchange between mother and fetus before placental circulation is established. Gross changes in its morphology and size therefore could indicate significant dysfunction of its maternofetal transport system and may be indicator of impending embryonic demise.[1]

This study aims to find out whether measurement of yolk sac obtained by TVS can be used to predict pregnancy outcome for care of pregnant females especially those ho suffer from recurrent pregnancy loss or those who conceived after infertility treatment and many others because for all, pregnancy is precious.

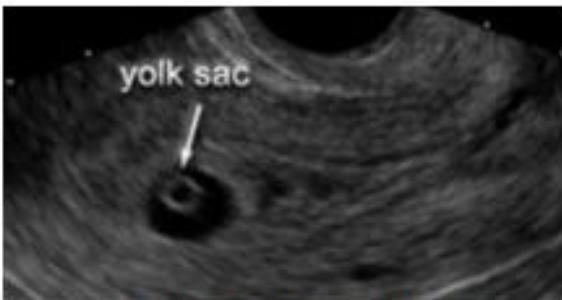

Normalyolk sac on TVS

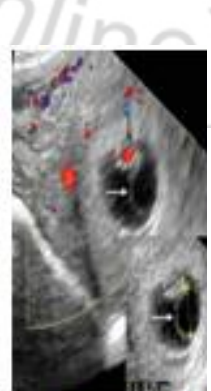

Large yolk

\section{Material \& Method}

The study of 100 singleton pregnancies has been conducted at HAL hospital, Bangalore. Women attending routine ANC clinics were offered an early TVS of 3.4-5 MHz transducer between 9-10 weeks of gestation.

\section{Inclusion criteria}

1) Women conceived spontaneously of after any treatment.

2) Pregnant women between 18-35 years of age.

3) 9-10 weeks period of gestation

4) Intrauterine pregnancies.

Exclusion criteria

1) Molar pregnancies

2) Known case of structural abnormalities of uterus \& cervix

Calculation of sample size: $n=t^{2} \times p(1-p) / m^{2}$

Where $\mathrm{n}=$ required sample size

$\mathrm{t}=$ confidence level at $95 \%$

$\mathrm{m}=$ margin of error at $5 \%$

$\mathrm{p}=$ estimated prevalence of abortion in pregnant ladies attending

HAL hospital, Bangalore ( $2 \%$ based on hospital statistics)

\section{Results}

100 patients were screened for yolk sac diameter by subjecting them to TVS at 9-10 weeks at HAL hospital, Bangalore \& followed up till delivery.

\section{Aims \& Objectives}

1) To investigate the role of yolk sac diameter in between 910 weeks of gestation by TVS in prediction of pregnancy in an unselected population.

2) To evaluate yolk sac diameter as predictor of pregnancy outcome.

\begin{tabular}{|c|c|c|}
\hline $\begin{array}{c}\text { Yolk sac diameter } \\
\text { Yolk sac } \\
\text { diameter(mm) }\end{array}$ & $\begin{array}{c}\text { No. of } \\
\text { patients }\end{array}$ & $\%$ \\
\hline 0 & 4 & $4.0 \%$ \\
\hline $1-2$ & 1 & $1.0 \%$ \\
\hline $2-6$ & 73 & $73 \%$ \\
\hline$>6$ & 22 & $22.0 \%$ \\
\hline Total & 100 & $100.0 \%$ \\
\hline
\end{tabular}




\section{International Journal of Science and Research (IJSR) ISSN (Online): 2319-7064 \\ Index Copernicus Value (2013): 6.14 | Impact Factor (2015): 6.391}

Correlation of age, gravida, previous H/O abortion, GDM, yolk sac diameter \& anembryonic gestation with incidence of abortion

\begin{tabular}{|c|c|c|c|}
\hline Clinical variable & \multicolumn{2}{|l|}{ Abortion } & $P$ value \\
\hline & No $(n=81)$ & Yes $(n=19)$ & \\
\hline \multicolumn{4}{|l|}{ Age in years } \\
\hline $18-20$ & $12(14.8 \%)$ & $1(5.3 \%)$ & \multirow{4}{*}{0.027} \\
\hline $21-25$ & $46(56.8 \%)$ & $6(31.6 \%)$ & \\
\hline $26-30$ & $21(25.9 \%)$ & $10(52.6 \%)$ & \\
\hline $31-35$ & $2(2.5 \%)$ & $2(10.5 \%)$ & \\
\hline \multicolumn{4}{|l|}{ Gravida } \\
\hline 1 & $60(74.1 \%)$ & $8(42.1 \%)$ & \multirow{3}{*}{0.013} \\
\hline 2 & $17(21 \%)$ & $8(42.1 \%)$ & \\
\hline $3 \&$ above & $4(4.9 \%)$ & $3(15.8 \%)$ & \\
\hline \multicolumn{4}{|l|}{ Previous $\mathrm{H} / \mathrm{O}$ abortion } \\
\hline No & $77(95 \%)$ & $15(78.9 \%)$ & \multirow[t]{2}{*}{0.040} \\
\hline Yes & $4(4.9 \%)$ & $4(21.1 \%)$ & \\
\hline \multicolumn{4}{|l|}{ GDM } \\
\hline Negative & $80(98.8 \%)$ & $9(47.4 \%)$ & \multirow[t]{2}{*}{$<0.001^{* *}$} \\
\hline Positive & $1(1.2 \%)$ & $10(52.6 \%)$ & \\
\hline \multicolumn{4}{|c|}{ Yolk sac diameter(mm) } \\
\hline$<6$ & $78(96.3 \%)$ & $0(0 \%)$ & \multirow[t]{2}{*}{$<0.001^{* * 2}$} \\
\hline$>6$ & $3(3.7 \%)$ & $19(100 \%)$ & \\
\hline \multicolumn{3}{|c|}{ Anembryonic gestation } & \\
\hline Negative & $77(95.1 \%)$ & $19(100 \%)$ & \multirow{2}{*}{$<0.001^{*}$} \\
\hline Positive & $0(0 \%)$ & $4(4.9 \%)$ & \\
\hline
\end{tabular}

Diagnostic role of yolk sac diameter to predict the incidence of abortion

\begin{tabular}{|c|c|c|c|c|c|}
\hline YSD vs abortion & TP & FP & FN & TN & Total \\
\hline Observation & 19 & 3 & 0 & 78 & 100 \\
\hline YSD vs abortion & Sensitivity & Specificity & PPV & NPV & Accuracy \\
\hline Evaluation & 100.00 & 96.30 & 86.36 & 100.00 & 97.00 \\
\hline
\end{tabular}

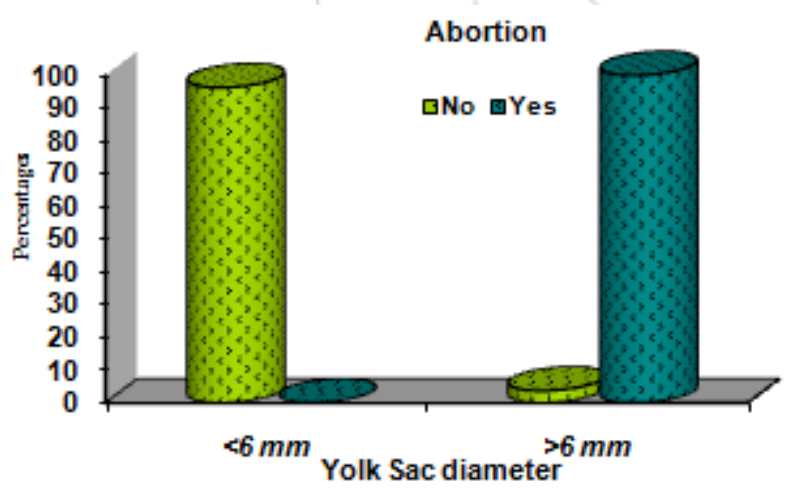

\section{Discussion}

The first trimester of pregnancy is the most crucial time as it carries maximum chances of abortion as compared to whole pregnancy. Fate of pregnancy many of the time is decided during this time. Infertile couple seeking treatment, elderly couples \& couples with previous bad outcome are under tremendous mental, emotional \& social pressures. The need of the day is to establish a tool which can accurately \& well in advance predict the fate of pregnancy. This study aims at finding out the use of yolk sac diameter for the same.

From decades, yolk sac within the early gestational sac is diagnostic of an intrauterine pregnancy \& is a reliable indicator of true gestational sac \& amnionicity. This study indicates that yolk sac diameter can be taken as a fairly accurate indicator of a successful pregnancy outcome when maximum yolk sac diameter is $<6 \mathrm{~mm}$ at $9-10$ weeks.

Nawal Rajni et al in 2012 defined abnormal yolk sac size as $>2$ SD above or below the mean yolk sac diameter for $6-10$ weeks. The maximum mean yolk sac diameter found in pregnancy with normal outcome was $5.5 \mathrm{~mm}$.[2]

Berdahl DM et al in 2010 concluded that mean yolk sac diameter $>5 \mathrm{~mm}$ in first trimester ultrasoundhas three fold increased risk for first trimester pregnancy loss independent of maternal risk factors.[3]

Rolo et al in 2009 found poor correlation between yolk sac volume in first trimester and gestational age.[4]

Fotios K et al in 2008 concluded that absence of yolk sac \& even smaller yolk sac diameter than expected for any gestational age are predictor of poor pregnancy outcome during first 12 weeks.[5]

Present study predicts that yolk sac diameter $>6 \mathrm{~mm}$ is a good predictor of poor pregnancy outcome.

\section{Conclusions}

The relationship between yolk sac diameter \& gestational age is linear \& direct till 10 weeks of gestational age, thereafter it decreases \& gradually disappears at 12 weeks. Yolk sac diameter at 9-10 weeks of gestation between 2-6 $\mathrm{mm}$ is significant to conclude successful pregnancy outcome. Yolk sac diameter $>6 \mathrm{~mm}$ is a good predictor of poor pregnancy outcome with sensitivity $100 \%$, specificity 96.3\%, PPV 86.36\%, NPV 100\%, accuracy 97\%. Yolk sac diameter $<2 \mathrm{~mm}$ predicts poor pregnancy outcome may be in terms of preterm deliveries or congenital abnormalities. Yolk sac diameter $0 \mathrm{~mm}$ is consistent with anembryonic gestation in $100 \%$ cases. DM contributes to large yolk sac diameter \& eventually missed abortions with $p$ value $<0.001$. yolk sac diameter should be included as essential parameter to be measured in first trimester dating scan to predict poor pregnancy outcome .

\section{References}

[1] Lindsay DJ, Lovett IS, Lyons EA, Levi CS, Zheng XH, Holt SC, et al. yolk sac diameter \& shape at endovaginal scan; predictors of pregnancy outcome at first trimester. Radiology.1992;183:115-118

[2] Nawal Rajani, Khuteta Sushila, Jain Deepika, Khuteta Rakesh P, Meena Vinay K. To assess value of yolk sac in predicting pregnancy outcome during first trimester: observational study; National Journal of Medical Research; July-Sept 2012;2:343-347

[3] Berdahl DM, B Laine J, Van Voorhis B, Dokras. Detection of large yolk sac on early ultrasound is associated with adverse pregnancy outcome. Fertile Steril; 2010;94:1535-1537

[4] Rolo LC, Nardozza CMM, Araujo E, Filho JB, Nowak PM, Moron AF. Correlation of yolk sac volume obtained by 3D ultrasound with gestational age at 7-10 weeks. Radiologia Brasileira;2009 Nov;6:42 


\section{International Journal of Science and Research (IJSR) \\ ISSN (Online): 2319-7064}

Index Copernicus Value (2013): 6.14 | Impact Factor (2015): 6.391

[5] Varelas FK, Prapas NM, Liang RI, Prapas IM, Makedos GA. Yolk sac size and embryonic heart rate as prognostic factor of first trimester pregnancy outcome. Europeon Journal Obstetrics \& Gynaecology Reproductive Biology;2008;138:10-13

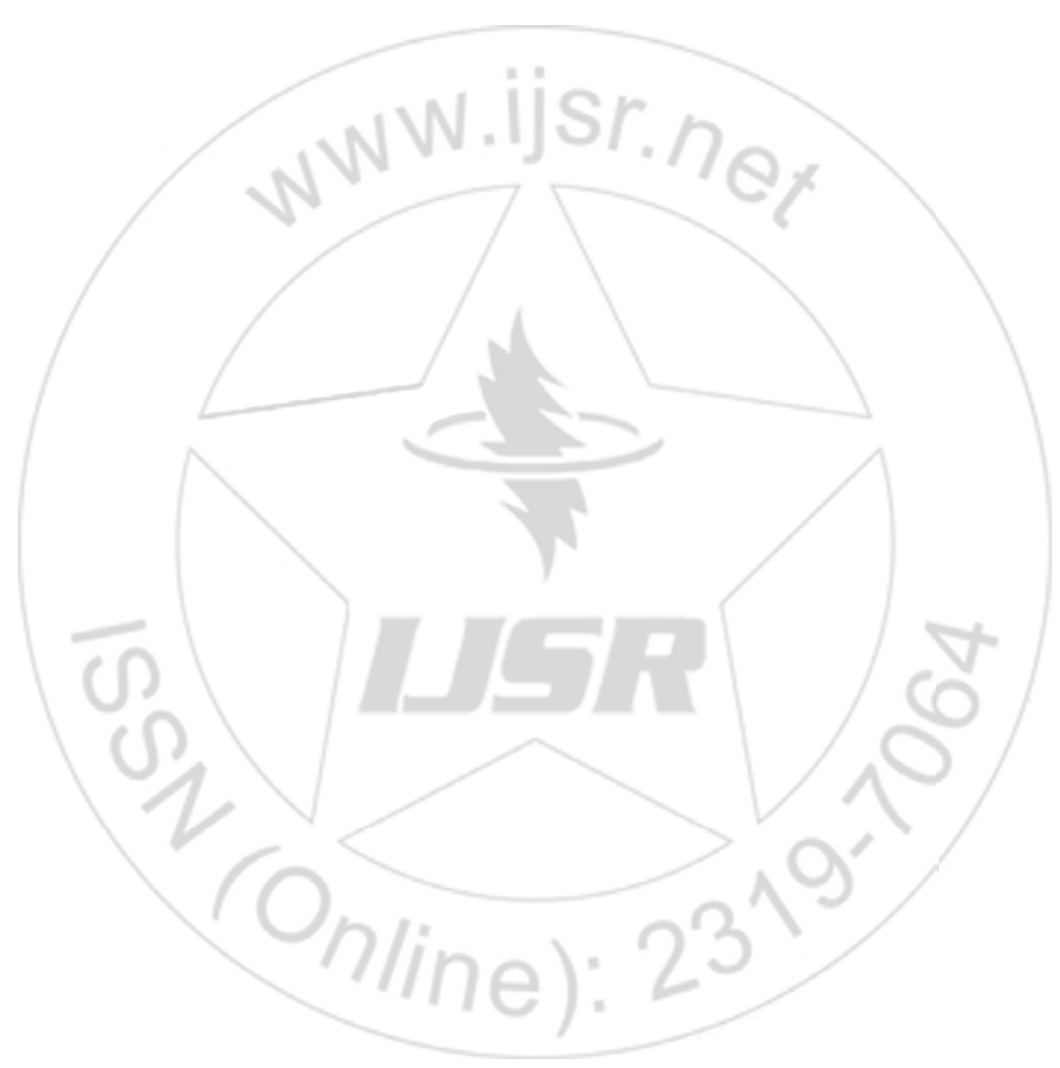

